\title{
Prevalence of Gastroesophageal Reflux Disease in Saudi Arabia
}

\author{
Obaidallah Buraykan Alsuwat ${ }^{\mathrm{a}}$, Abdulrahman Ahmad Alzahrani ${ }^{\mathrm{a}, \mathrm{c}}$, \\ Mohammed Abdullah Alzhrania, Ali Mesfer Alkhathamia, \\ Mohammad Eid Mahmoud Mahfouz ${ }^{\mathrm{a}, \mathrm{b}}$
}

\begin{abstract}
Background: Gastroesophageal reflux disease (GERD) is a common chronic gastrointestinal tract disease. The incidence is higher in Asian and Arab countries. In Saudi Arabia, there are few studies that have assessed the prevalence of GERD among some cities' communities. Hence, this study aims to study the prevalence of GERD among the general population of Saudi Arabia.
\end{abstract}

Methods: A cross-sectional study was designed to determine the prevalence of GERD among the community of Saudi Arabia. The sample was randomly gathered through self-administered validated GERD questionnaire (GerdQ) to diagnose GERD, during the period from November to December 2016. The sociodemographic data was assessed for all participants. The data were analysed using Statistical Package for Social Sciences version 21.0 (SPSS); the $t$-test was used to assess the association of GERD and sociodemographic data.

Results: The sample was comprised of 2,043 participants. Female and male were $51.8 \%$ and $48.2 \%$, respectively. Mean age was 29.6 years with the standard deviation of 10.5 years. The GERD prevalence was $28.7 \%$. It was found statistically significant among divorced/widow $(34.9 \%, \mathrm{P}=0.003)$. In contrast, there was no association between GERD's prevalence and gender, age, residence status, education level, occupation, and blood group $(\mathrm{P}>0.05)$.

Conclusions: The prevalence of GERD among Saudi population is higher than that in Western countries and East Asia. It affects divorced/widow, obese and those with a sedentary lifestyle. It is advocated that national programs and educational campaigns for prevention of this disease and its complications should be established.

Keywords: GERD; Reflux; Prevalence; Saudi Arabia

Manuscript submitted December 4, 2017, accepted January 3, 2018

${ }^{\mathrm{a} C}$ College of Medicine, Taif University, Taif, Saudi Arabia

${ }^{b}$ Chairman of Surgery at King Abdul Aziz Specialist Hospital, Taif, Saudi Arabia ${ }^{\mathrm{c} C}$ Corresponding Author: Abdulrahman Ahmad Alzahrani, College of Medicine, Taif University, Taif, Saudi Arabia. Email: aakz1415@gmail.com

doi: https://doi.org/10.14740/jocmr3292w

\section{Introduction}

A healthy individual typically has a physiological backflow of the gastric contents to the esophagus. When these refluxes cause uncomfortable symptoms such as heartburn and/or acid regurgitation, additional to an injury of the esophageal mucosa for not less than once per week, that is called "gastroesophageal reflux disease (GERD)" [1].

GERD has a large negative impact on the health care systems and patients' health-related quality of life [2]. In addition, the irritation of esophagus mucosa by the acid reflux will be followed by metaplasia (Barrett's esophagus), that are finally result in esophagus adenocarcinoma [3].

The estimated range of GERD prevalence in the Middle East was $8.7-33.1 \%$ [4]. Most of the researches done in the Middle East came from Iran which reported a high prevalence of $33 \%$ compared to the Western countries of $28 \%$ [5].

In Saudi Arabia, based on two studies conducted in the west region and Riyadh using the GerdQ questionnaire with a score of $\geq 8$ as the diagnostic criteria of GERD, the prevalence range of GERD was $23.47 \%-45.4 \%$ [5, 6]. Also, there was one retrospective study reported the prevalence of GERD in the south of Saudi Arabia 15\% [7].

Since there are 13 regions in Saudi Arabia and there is no previous study to assess the prevalence of GERD in these regions, this study aimed to determine the prevalence of GERD and assess its relations with sociodemographic data in a random cohort of Saudi Arabia.

\section{Methods}

A cross-sectional study was designed to assess the prevalence of GERD and its sociodemographic associations among the communities of Saudi Arabia. The minimum sample size that should be achieved is 385 subjects that represent the Saudi population (20 millions) with a confidence level (CL) of $95 \%$ and confidence interval (CI) 5\%. The sample of 2,043 individuals (CL: $99 \%$; CI: $2.85 \%$ ) was collected randomly using a self-administered questionnaire on the website and by trained medical students through interviewing general population, during the period from November 1 to December 22, 2016. The ethics approval was acquired from the Research Ethics Committee at Taif University (Application Number: 38-36-0043). 
The questionnaire included two parts: 1) The first part was to collect the sociodemographic data (gender, age, marital status, residence, educational level, occupation, and blood group), 2) the second part was the GerdQ, which is the diagnostic tool for the GERD. GerdQ is composed of six questions, of which four questions are about the positive GERD predictors (heartburn, regurgitation, sleep disturbance due to the heartburn and regurgitation and using over the counter (OTC) medications) and two questions about the negative GERD predictors (nausea and epigastric pain).

\section{Data collection}

There is no available validated Arabic GerdQ. So that, the questionnaires were translated from English to Arabic and then conducted by trained medical students through interviews with the general population in the malls, hospitals, primary health care centres, universities, and schools. Also, the online questionnaire (website: http://cutt.us/GERDq) was shared through the social media applications such as WhatsApp, Telegram, Twitter, Facebook, and Instagram. Prior to data collection, all participants were informed about the nature of the study and the voluntary nature of their participation. The electronic consents were obtained from those who agreed to participate in the study through the website. We included all Saudi participants who are over 18 years old and capable to understand the questionnaire.

\section{GerdQ score}

The scoring of GerdQ is depending on the frequency of these symptoms during the last week (less than once, once, 2 - 3 times and $4-7$ times, respectively), where the scores ranging from 0 to 3 for the positive GERD predictors and reversed order for the negative GERD predictors $(3=$ none $)$. After summation of the scores, the patient who got 8 of score or more was considered as having GERD. The GerdQ sensitivity and specificity for the GERD diagnosis was $65 \%$ and $71 \%$, respectively [8].

\section{Statistical analysis}

The data were entered using Microsoft Excel 2010, and translated back from Arabic to English. Then, it was analysed using Statistical Package for the Social Sciences SPSS program version 21.0. Data analysis included descriptive statistics as well as the $t$-test for comparison between groups. A statistical significant is considered when $\mathrm{P}$ value $<0.05$.

\section{Results}

\section{Prevalence of GERD}

The prevalence of GERD among the participants was $28.7 \%$ (n

\section{Prevalence of GERD in Saudi Arabia}

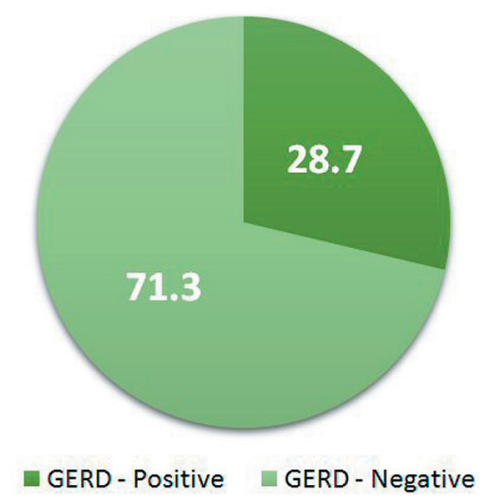

Figure 1. Figure 1. The prevalence of GERD in Saudi Arabia $(n=$ 2,043). GERD: gastroesophageal reflux diseas.

= 587) (Fig. 1). There were no statistically significant differences between GerdQ results and gender, age group, residence, education, occupation, and blood group $(\mathrm{P}>0.05)$. The statistically significant differences between GerdQ results and the sociodemographic data are documented in Table 1.

\section{Sociodemographic data}

The total number of participants in our study was 2,043 . Totally, $1,059(51.8 \%)$ of them were female and $984(48.2 \%)$ were male. The average of ages was 29.6 years, and as for the standard deviation 10.5 years. Single participants formed $51.7 \%$, married were $46.2 \%$ while divorced or widow were $2.1 \%$. The participants with living in urban areas were $88.9 \%$ and $11.1 \%$ for rural areas. The educational levels of the participants were university or above $77.7 \%$, high school $19.1 \%$, primary or intermediate school $2.2 \%$ and illiteracy $1 \%$. A total of $43 \%$ of participants were students, $36.5 \%$ employees, $8.6 \%$ unemployed, $8.3 \%$ housewives, $2.2 \%$ retired, $1.5 \%$ manual workers.

The blood groups $\mathrm{O}+, \mathrm{O}-, \mathrm{A}+, \mathrm{A}-, \mathrm{B}+, \mathrm{B}-, \mathrm{AB}+$, and $\mathrm{AB}-$ were $43.1 \%, 5.1 \%, 23.3 \%, 2 \%, 10.6 \%, 1.2 \%, 4 \%$ and $0.4 \%$, respectively. The statistically significant difference between GERD and sociodemographic data are documented in Table 1.

\section{Discussion}

GERD is a group of symptoms resulting from reflux of the stomach contents, which causes esophageal or extra esophageal manifestations. There were few studies conducted in the Gulf region to assess the GERD prevalence [6]. Two studies of them were similar to our study and they were conducted in Riyadh and the Western region of Saudi Arabia, in which the prevalence was $45.4 \%-23.47 \%$, respectively [5, 6]. Also, another study was done in Qassim region among 200 Saudi school teachers has reported the overall prevalence was 55\% [9]. Two retrospective studies conducted in Abha and Jizan (Southern region of Saudi Arabia) using upper gastrointestinal 
Table 1. Association of GERD With Sociodemographic Data $(n=2,043)$

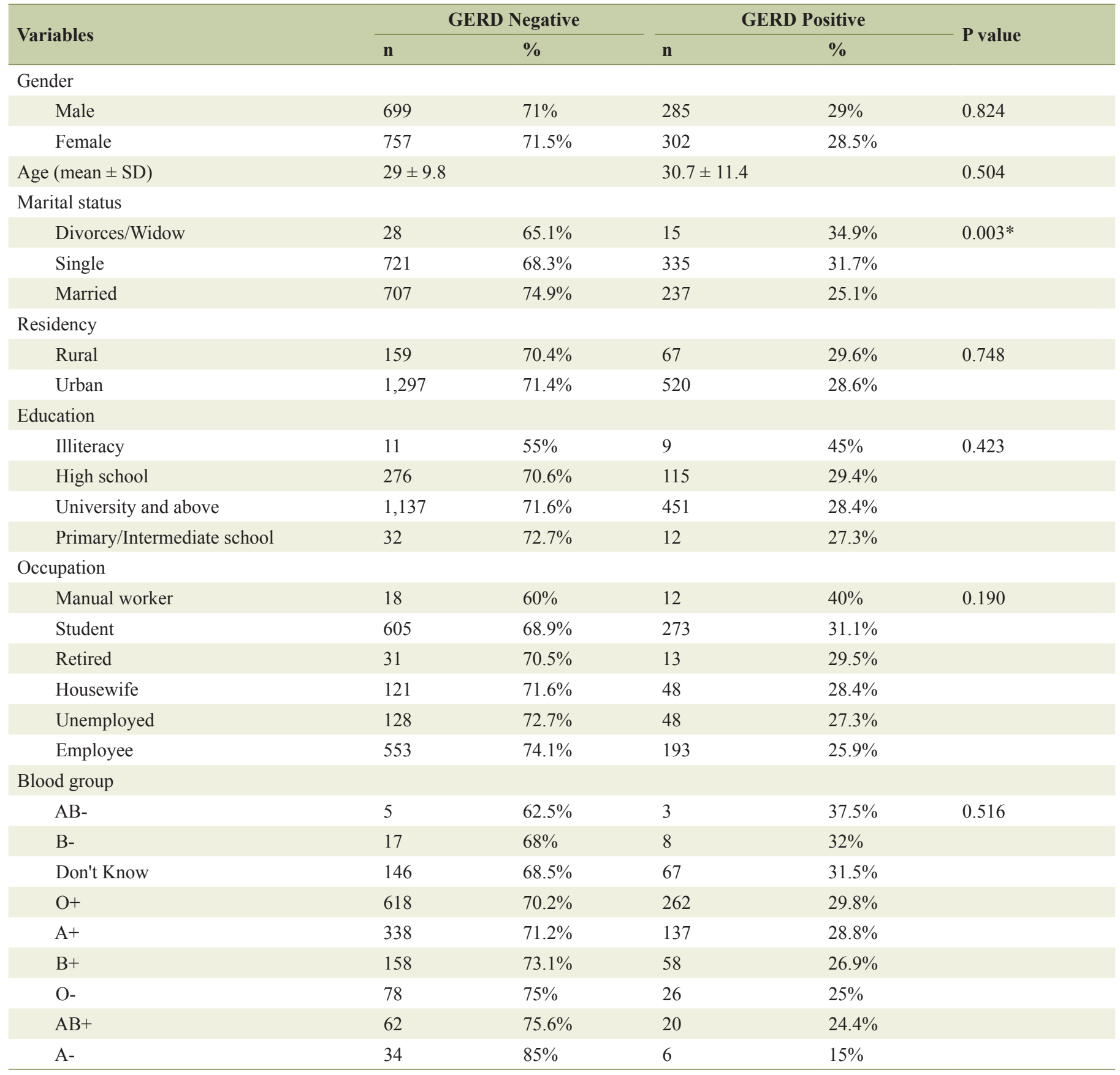

GERD: gastroesophageal reflux disease; SD: standard deviation. *Statistical significant.

endoscopy to diagnose GERD and its complications, in which the GERD prevalence was $15 \%$ in Abha and the prevalence of Barrett's oesophagus was $0.003 \%$ in Jizan $[7,10]$.

In our study, the prevalence of GERD (28.7\%) was lower than a study reported in Riyadh (Saudi Arabia capital city) and higher than a study that was conducted in the Western region of Saudi Arabia [5, 6]. The range of GERD prevalence was 2.5-7.8\% in East Asia, 11.6\% in Australia, 23\% in South America, 8.7-33.1\% in the Middle East, 18.1-27.8\% in North
America and 8.8-25.9\% in Europe [4].

As shown in (Table 1), marital status was a significant factor with reflux symptoms. The high prevalence of GERD was obvious among divorced/widow and followed by the single. Most of the previous studies found a significant association between GERD and marital status [11-13]. We surmise the explanation of this high prevalence of GERD among those divorced/ widows is due to psychological stresses, which can develop the GERD symptoms [14]. 
As shown in (Table 1), we did not find a significant association between age and GERD symptoms. Some studies were compatible with our study $[15,16]$, but other studies have found an association between GERD and age [17, 18]. In some studies the age was expressed as arbitrary cut-off $[15,16,18]$, while others expressed the age as a continuous variable [17]. This variation in the methods may lead to this difference between studies.

Female gender has been reported as a risk factor with GERD in previous studies $[12,13]$, but other studies have not revealed a relationship between gender and GERD $[19,20]$. This finding is similar to our study. We did not demonstrate any relationship between reflux symptoms and residency for the first time $(\mathrm{P}>0.05)$. A previous study showed that people living in a rural community have a higher risk of GERD [12]. While other studies found that subjects living in an urban community have a higher risk of GERD; this could be due to psychological factors [21-24].

Previous studies have shown that reflux symptoms were less with high educational level $[25,26]$, while other studies have found that subjects with low educational level were higher in the prevalence of reflux symptoms. This variation may be attributed to some unhealthy lifestyle factors in subjects with low educational level $[12,13,27]$. Our results demonstrated no correlation between educational level and GERD.

There is a previous study from China that showed a significant relationship between the occupation and GERD [28]. In our study, we found no association. This may be due to the increase in the number of working hours in China compared to Saudi Arabia, we need another study that proves or deny this.

In relation to blood group, there was a high frequency of AB- blood group in gastroesophageal reflux patients but there was no a correlation between blood group and GERD. This finding is identical to other studies $[9,29]$. Patients with blood group A and diagnosed with GERD have more likely to develop Barret's esophagus or even esophageal cancer suggesting a genetic susceptibility, but patient of blood type $\mathrm{O}$ has been shown to have an association with high stomach acid production and is much more likely to develop reflux symptoms [30].

\section{Conclusions}

The prevalence of GERD in Saudi population is slightly higher than Western countries and much higher than countries of East Asia. It affects divorced/widow, obese and those with sedentary lifestyle. We must establish national programs and educational campaigns to keep prevention of this disease and its complications.

\section{Acknowledgments}

We would like to extend special acknowledgement to Hebatullah Abdulaziz Alshehri, Jumanah Talal Al-Malki, Lojain Abdul Aziz Al-Shehri, Reham Othman Alzahrani and Sara Mohammed Salem Alosaimi, for their valuable efforts and active role in data collection.

\section{Conflict of Interest}

No conflict of interest.

\section{Financial Support}

None.

\section{References}

1. Bredenoord AJ, Pandolfino JE, Smout AJ. Gastro-oesophageal reflux disease. Lancet. 2013;381(9881):1933-1942.

2. Lee SW, Lee TY, Lien HC, Peng YC, Yeh HJ, Chang CS. Correlation between symptom severity and health-related life quality of a population with gastroesophageal reflux disease. Gastroenterology Res. 2017;10(2):78-83.

3. Wang RH. From reflux esophagitis to Barrett's esophagus and esophageal adenocarcinoma. World J Gastroenterol. 2015;21(17):5210-5219.

4. El-Serag HB, Sweet S, Winchester CC, Dent J. Update on the epidemiology of gastro-oesophageal reflux disease: a systematic review. Gut. 2014;63(6):871-880.

5. Binhussein M, Alamoudi A, Bajawi A, Alghafis M, Baz M, Bakhsh R, et al. Prevalence of gastro-oesophageal reflux in western region of Saudi Arabia. Saudi J Gastroenterol. 2016;22(7):pS13. Retrieved from: http://www.saudijgastro.com/article.asp?issn=1319-3767; year=2016; vol ume $=22 ;$ issue $=7$; spage $=1$; epage $=24$; aulast $=$.

6. Almadi MA, Almousa MA, Althwainy AF, Altamimi AM, Alamoudi HO, Alshamrani HS, Alharbi OR, et al. Prevalence of symptoms of gastroesopahgeal reflux in a cohort of Saudi Arabians: a study of 1265 subjects. Saudi J Gastroenterol. 2014;20(4):248-254.

7. Al-Humayed SM, Mohamed-Elbagir AK, Al-Wabel AA, Argobi YA. The changing pattern of upper gastro-intestinal lesions in southern Saudi Arabia: an endoscopic study. Saudi J Gastroenterol. 2010;16(1):35-37.

8. Jones R, Junghard O, Dent J, Vakil N, Halling K, Wernersson B, Lind T. Development of the GerdQ, a tool for the diagnosis and management of gastro-oesophageal reflux disease in primary care. Aliment Pharmacol Ther. 2009;30(10):1030-1038.

9. Altwigry AM, Almutairi MS, Ahmed M. Gastroesophageal reflux disease prevalence among school teachers of Saudi Arabia and its impact on their daily life activities. Int J Health Sci (Qassim). 2017;11(2):59-64.

10. Gadour MO, Ayoola EA. Barrett's oesophagus and oesophageal cancer in Saudi Arabia. Trop Gastroenterol. 1999;20(3):111-115.

11. Pourhoseingholi A, Pourhoseingholi MA, MoghimiDehkordi B, Barzegar F, Safaee A, Vahedi M, Dulaimi DA, et al. Epidemiological features of gastro-esophageal reflux disease in Iran based on general population. Gastroenterol Hepatol Bed Bench. 2012;5(1):54-59.

12. Diaz-Rubio M, Moreno-Elola-Olaso C, Rey E, Locke GR, 3rd, Rodriguez-Artalejo F. Symptoms of gastro-oe- 
sophageal reflux: prevalence, severity, duration and associated factors in a Spanish population. Aliment Pharmacol Ther. 2004;19(1):95-105.

13. Shaha M, Perveen I, Alamgir MJ, Masud MH, Rahman MH. Prevalence and risk factors for gastro-esophageal reflux disease in the North-Eastern part of Bangladesh. Bangladesh Med Res Counc Bull. 2012;38(3):108-113.

14. Naliboff BD, Mayer M, Fass R, Fitzgerald LZ, Chang L, Bolus R, Mayer EA. The effect of life stress on symptoms of heartburn. Psychosom Med. 2004;66(3):426-434.

15. Nasseri-Moghaddam S, Mofid A, Ghotbi MH, Razjouyan H, Nouraie M, Ramard AR, Zaer-Rezaie H, et al. Epidemiological study of gastro-oesophageal reflux disease: reflux in spouse as a risk factor. Aliment Pharmacol Ther. 2008;28(1):144-153.

16. Chen M, Xiong L, Chen H, Xu A, He L, Hu P. Prevalence, risk factors and impact of gastroesophageal reflux disease symptoms: a population-based study in South China. Scand J Gastroenterol. 2005;40(7):759-767.

17. Mohammed I, Cherkas LF, Riley SA, Spector TD, Trudgill NJ. Genetic influences in gastro-oesophageal reflux disease: a twin study. Gut. 2003;52(8):1085-1089.

18. He J, Ma X, Zhao Y, Wang R, Yan X, Yan H, Yin P, et al. A population-based survey of the epidemiology of symptom-defined gastroesophageal reflux disease: the Systematic Investigation of Gastrointestinal Diseases in China. BMC Gastroenterol. 2010;10:94.

19. Goh KL, Chang CS, Fock KM, Ke M, Park HJ, Lam SK. Gastro-oesophageal reflux disease in Asia. J Gastroenterol Hepatol. 2000;15(3):230-238.

20. Locke GR, 3rd, Talley NJ, Fett SL, Zinsmeister AR, Melton LJ, 3rd. Prevalence and clinical spectrum of gastroesophageal reflux: a population-based study in Olmsted County, Minnesota. Gastroenterology. 1997;112(5):14481456.

21. Sharma PK, Ahuja V, Madan K, Gupta S, Raizada A, Sharma MP. Prevalence, severity, and risk factors of symptomatic gastroesophageal reflux disease among employees of a large hospital in northern India. Indian J Gastroenterol. 2011;30(3):128-134.

22. Jones RH, Hungin APS, Phillips J, Mills JG. Gastrooesophageal reflux disease in primary care in Europe: clinical presentation and endoscopic findings. Eur J Gen Pract. 1995;1(4):149-154.

23. Baker LH, Lieberman D, Oehlke M. Psychological distress in patients with gastroesophageal reflux disease. Am J Gastroenterol. 1995;90(10):1797-1803.

24. Boltin D, Boaz M, Aizic S, Sperber A, Fass R, Niv Y, Dickman R. Psychological distress is not associated with treatment failure in patients with gastroesophageal reflux disease. J Psychosom Res. 2013;75(5):462-466.

25. Cela L, Kraja B, Hoti K, Toci E, Muja H, Roshi E, Burazeri G. Lifestyle characteristics and gastroesophageal reflux disease: a population-based study in Albania. Gastroenterol Res Pract. 2013;2013:936792.

26. Wang HY, Leena KB, Plymoth A, Hergens MP, Yin L, Shenoy KT, Ye W. Prevalence of gastro-esophageal reflux disease and its risk factors in a community-based population in southern India. BMC Gastroenterol. 2016;16:36.

27. Zheng Z, Nordenstedt H, Pedersen NL, Lagergren J, Ye W. Lifestyle factors and risk for symptomatic gastroesophageal reflux in monozygotic twins. Gastroenterology. 2007;132(1):87-95.

28. Niu CY, Zhou YL, Yan R, Mu NL, Gao BH, Wu FX, Luo JY. Incidence of gastroesophageal reflux disease in Uygur and Han Chinese adults in Urumqi. World J Gastroenterol. 2012;18(48):7333-7340.

29. Sadreddini M, Rasmi Y, Maleki T. Frequency of ABO and $\mathrm{Rh}$ blood groups in gastro esophageal reflux disease. JBUMS. 2011;13(4):73-77.

30. Torrado J, Ruiz B, Garay J, Asenjo JL, Tovar JA, Cosme A, Correa P. Blood-group phenotypes, sulfomucins, and Helicobacter pylori in Barrett's esophagus. Am J Surg Pathol. 1997;21(9):1023-1029. 